\title{
COVID-19 Fear, Mental Health, and Substance Misuse Conditions Among University Social Work Students in Israel and Russia
}

\author{
Mor Yehudai $^{1}$ - Shmaya Bender ${ }^{1}$ - Valentina Gritsenko ${ }^{2}$ - Vsevolod Konstantinov ${ }^{3}$. \\ Alexander Reznik ${ }^{1} \cdot$ Richard Isralowitz $^{1}$ (D)
}

Published online: 6 July 2020

(C) Springer Science+Business Media, LLC, part of Springer Nature 2020

In December 2019, cases of pneumonia of unknown etiology but with acute respiratory distress syndrome (ARDS) and other serious complications were reported in Wuhan, Hubei Province, China. One month later, a novel coronavirus was identified by the Chinese Center for Disease Control and Prevention (CDC) from the throat swab sample of a patient and was subsequently named "COVID-19" by the World Health Organization (WHO) (Nanshan et al. 2020). At the end of June 2020, approximately 500,000 deaths worldwide have been linked to COVID-19 (Johns Hopkins University of Medicine 2020).

Following many cases reported by Chinese authorities, the WHO declared the new coronavirus pneumonia epidemic a public health emergency of international concern. Among the early virus characteristics reported were strong human-to-human transmission and fast transmission speed, mainly spread through respiratory droplets and contact (Nanshan et al. 2020). In response, Chinese authorities moved to a strategy of regional blockade aimed to stop the spread of the epidemic (Chen et al. 2020) as well as quarantine. "Quarantine" is one of the oldest and most effective tools of controlling communicable disease outbreaks. It means the restriction of movement among people presumed to have been exposed to a contagious disease but are not ill, either because they did not become infected or because they are still in the incubation period. The second tool that is widely used to prevent the spread of the pandemic is "social distancing." It is designed to reduce interactions between people in a community where individuals may be infectious but have not yet been identified, and hence not yet isolated (Burdorf et al. 2020).

Once countries dealing with COVID-19 implemented quarantine and social distancing, the need for social workers and other health care professionals greatly increased due to mental

Richard Isralowitz

Richard@bgu.ac.il

1 Regional Alcohol and Drug Abuse Research Center, Ben Gurion University of the Negev, 84105 Beer Sheva, Israel

2 Department of Social Psychology, Moscow State University of Psychology and Education, Moscow, Russia

3 Department of General Psychology, Penza State University, Penza, Russia 
health problems experienced by the general public. Studies have found that widespread outbreaks of infectious diseases, such as COVID-19, are associated with psychological distress and mental illness (Bao et al. 2020). Such conditions include stress, anxiety, depression, insomnia, anger, fear, stigma (Lin 2020; Pakpour and Griffiths 2020; Torales et al. 2020), and substance misuse (Baillie et al. 2010) on individual, family, community, and national levels (Harper et al. 2020; Kang et al. 2020). Older adults, especially with chronic health conditions, have been identified as extremely vulnerable to COVID-19. However, those dealing with the infection, such as medical and allied health personnel including those affiliated with social work, have received considerable attention for their "front line" efforts combating this disaster.

Israel and Russia pursue a similar policy to combat the COVID-19: strict quarantine or selfisolation, the abolition of all events with a large number of people, the closure of schools and universities, the cessation of aviation and railway travel and closed borders, the mandatory use of masks, etc. At the end of June 2020, there were 22,800 confirmed cases and 314 deaths in Israel and in Russia, 626,779 cases and 8958 deaths (JHUM 2020). Based on the dearth of information about student mental health during the COVID-19 pandemic (Grubic et al. 2020), we hypothesized fear, mental health, and substance misuse among university students are similar regardless of nationality. For this purpose, social work students from Israel and Russia were studied.

\section{Methods}

\section{Design, Participants, and Procedures}

The Qualtrics software platform was used for this online survey. The main data collection instrument was the seven-item Fear of COVID-19 Scale (FCV-19S) (Ahorsu et al. 2020). Adapted versions of FCV-19S are used in different countries (Alyami et al. 2020; Reznik et al. 2020; Satici et al. 2020). The levels of agreement with FCV-19S statements were evaluated by a 5-point Likert scale from 1 (strongly disagree) to 5 (strongly agree). Higher total scores correspond with more COVID-19 fear. Two questions were added to the scale to determine COVID-19 impact on university student studies, social life, and family relations.

The influence of COVID-19 on student mental health (i.e., depression, exhaustion, loneliness, nervousness, and anger) as well as substance use including tobacco, alcohol, and cannabis was examined. Three open-ended questions were added about stress, substance use, and other COVID-19-related concerns. The survey instrument, prepared in English, was translated to Hebrew and Russian and back translated. The translation method used is consistent with that described by the World Health Organization for research purposes (WHO 2020). The Hebrew and Russian versions of the instrument are available on request.

To ensure the methods proposed for this research were ethical, the Israeli and Russian investigators received approval from the ethics committees of the two universities involved. These ethics approval processes are equivalent to established regulations to help protect the rights and welfare of human research subjects (Breault 2006). No external grant funding was received for the study.

The universities involved in this study conduct distance learning linking students, lecturers, and departments. This capacity was used for data collection. Students in both countries were informed about the online survey. Before responding to the survey questions, the survey aim 
was explained along with assurance of response confidentiality and compliance with all ethical standards. Students were informed their responses to the survey constituted consent to participate in the survey. The survey respondents included 291 social work students from Israel $(N=170)$ and Russia $(N=121)$.

\section{Statistical Analysis}

The Cronbach's reliability of the FCV-19S with two additional questions is 0.827 . Because the coefficient may not be the best way of judging the reliability of an instrument (Cronbach and Shavelson 2004; Dunn et al. 2014), McDonald's Omega was conducted alongside Cronbach's alpha (McDonald 1999). The McDonald's Omega score for FCV-19S is 0.845 . For this study, all statistical analyses were conducted using SPSS, version 25, and JASP, a free and opensource program for statistical analysis supported by the University of Amsterdam (JASP 2020). The Pearson's chi-square test for nominal (categorical) data, t-test, and one-way ANOVA for continuous variables were used. Fear levels, based on fear scale responses close to a normal distribution (asymmetry $=0.467$; kurtosis $=-0.120$ ), were divided into three parts of $33 \%$ each. This allowed us to report three levels of student COVID-19 fearlow, medium, and high.

\section{Results}

Among the 291 survey respondents, $83.2 \%(N=242)$ were female, $15.8 \%(N=46)$ male, and $1.0 \%(N=3)$ other. The mean age of the respondents is 24.4 years $(\mathrm{SD}=5.5)$, and $58.5 \%(N=$ $169)$ reported being not religious and $41.5 \%(N=120)$ religious. Table 1 provides background characteristics of the survey respondents.

For all respondents, the mean value of the FCV-19S is $22.0(\mathrm{SD}=6.3)$ and median $=21.0$, with a range of 9 to 41 . Based on the distribution of results, the fear values were gradated ranging from 9 of 41 to represent the following levels: low 9 to 18 scores $(N=87)$; medium 19 to 24 scores $(N=97)$; and, high $25-41$ scores $(N=89)$. Figure 1 shows the total distribution of the fear values among the Israeli and Russian students.

Results evidence no significant difference in fear values based on nationality and religiosity (i.e., secular or religious). However, females reported higher fear levels, on average, than

Table 1 Student demographic characteristics

\begin{tabular}{llll}
\hline & Israel $(N=170)$ & Russia $(N=121)$ & Total $(N=291)$ \\
\hline Gender, \% $(N)$ & $* * *$ & $* * *$ & $15.8(46)$ \\
Male & $9.4(16)$ & $24.8(30)$ & $83.2(242)$ \\
Female & $88.8(151)$ & $75.2(91)$ & $1.0(3)$ \\
Other & $1.8(3)$ & $0.0(0)$ & $24.4(5.5)$ \\
Age, mean $(\mathrm{SD})$ & $24.9(2.2)$ & $23.7(8.1)$ & 24.0 \\
Median & 25.0 & 21.0 & $(17-57)$ \\
Range & $(19-39)$ & $(17-57)$ & $58.5(169)$ \\
Religious, $\%(N)$ & $* * *$ & $* * *$ & $41.5(120)$ \\
Not religious & $69.2(117)$ & $43.3(52)$ & \\
Religious & $30.8(52)$ & $56.7(68)$ & \\
\hline
\end{tabular}

$* * * p<.001\left(\chi^{2}\right.$ test $)$ 
$\mathrm{n}$

\section{Distribution of COVID-19 Fear Scores by Country}

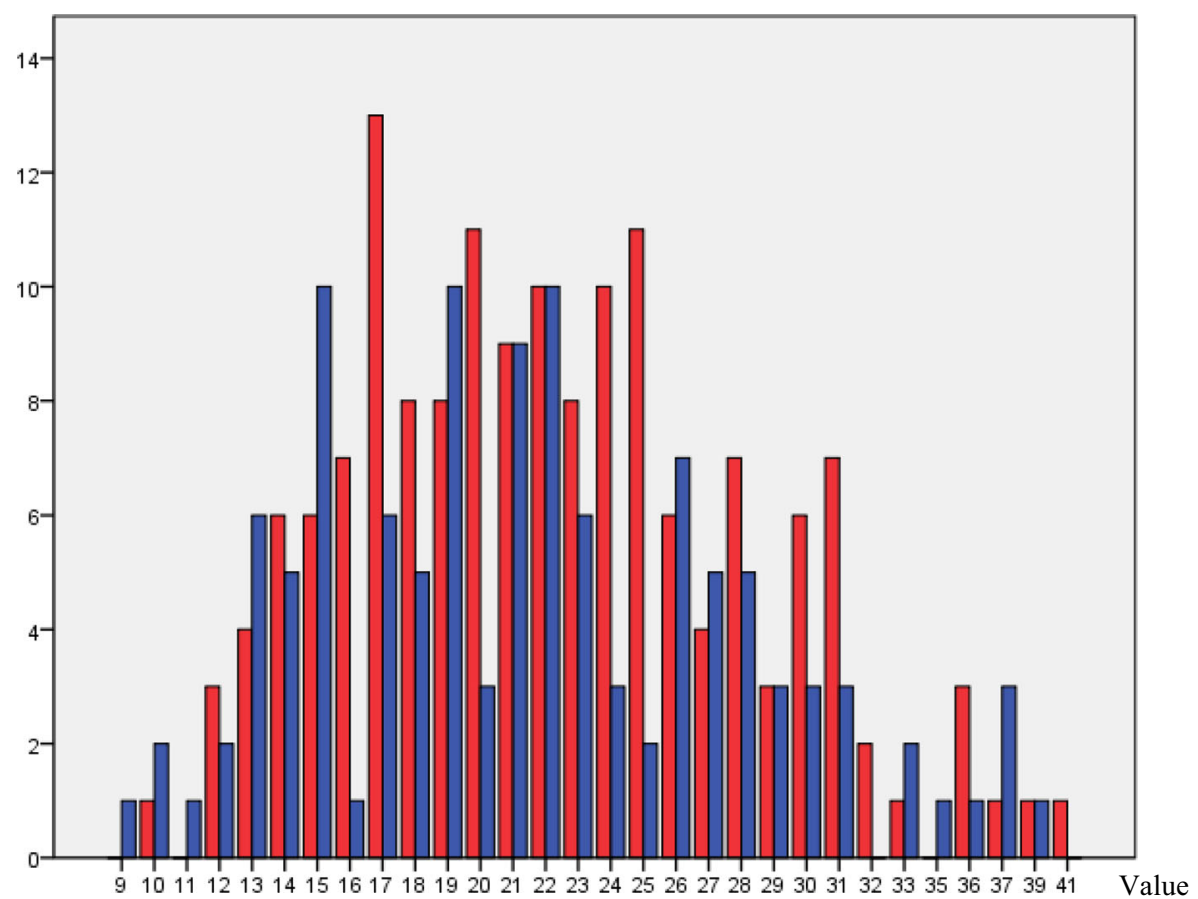

\section{Israel}

Russia

Fig. 1 Distribution of COVID-19 fear scores by country

males (22.4 vs. 19.7 respectively; $t_{268}=2.674 ; p=.008$ ). Last month, substance use rates before COVID-19, for all students, were $39.3 \%$ cigarettes, $71.9 \%$ alcohol, and, $23.2 \%$ cannabis. Israeli students reported more alcohol $(81.3 \%$ vs. $60.0 \% ; p<.001)$ and cannabis $(39.3 \%$ vs. $0.9 \% ; p<.001)$ use than those in Russia where the substance is strictly prohibited. Regardless of nationality, secular more than religious students reported higher levels of cigarette ( $45.7 \%$ vs. $31.6 \% ; p=.020)$, alcohol $(83.0 \%$ vs. $57.4 \% ; p<.001)$, and cannabis $(29.7 \%$ vs. $14.7 \% ; p=.005)$ use. Survey respondents who used substances prior to the COVID-19 reported more than usual use during the quarantine and social distancing period. The percentage of substance users reporting COVID-19-related increase is cigarettes $(43.7 \%)$; alcohol (38.9\%); and cannabis (52.5\%). Only alcohol evidenced a higher level based on gender. Males more than females reported an increase $(70.0 \%$ vs. $33.1 \% ; p<.001)$. Binge drinking due to COVID-19 was reported by $10.8 \%$ Israeli and $14.2 \%$ Russian students, male significantly more than female students $(31.0 \%$ vs. $9.0 \% ; p<.001)$.

Findings show COVID-19 linked to levels of depression (45.8\%); exhaustion (51.8\%); loneliness $(58.8 \%)$; nervousness (48.5\%); and anger (43.1\%). Israeli, more than Russian, students expressed higher levels of exhaustion and loneliness (see Tables 2 and 3). Table 4 shows the impact of COVID-19 fear on student emotional conditions. 
Table 2 During the last month, because of COVID-19, have you felt more

\begin{tabular}{llll}
\hline & Israel $(N=170)$ & Russia $(N=121)$ & Total $(N=291)$ \\
\hline Depressed, \% $(N)$ & $45.3(68)$ & $46.4(52)$ & $45.8(120)$ \\
Exhausted, \% $(N)$ & $63.1(94)^{* * *}$ & $35.8(38)^{* * *}$ & $51.8(132)$ \\
Lonely, \% $(N)$ & $66.0(99)^{* *}$ & $48.6(51)^{* *}$ & $58.8(150)$ \\
Nervous, \% $(N)$ & $46.7(70)$ & $50.9(58)$ & $48.5(128)$ \\
Angry, \% $(N)$ & $42.3(63)$ & $44.2(46)$ & $43.1(109)$ \\
\hline
\end{tabular}

$* * p<.01 ; * * * p<.001\left(\chi^{2}\right.$ test $)$

A two-way ANOVA shows nationality and emotional conditions not linked to COVID-19 fear scores: $\mathrm{F}_{1,254}=.038 ; p=.845$ for depression; $\mathrm{F}_{1,247}=.248 ; p=.619$ for exhaustion; $\mathrm{F}_{1,248}=1.312 ; p=.253$ for loneliness; $\mathrm{F}_{1,256}=.926 ; p=.337$ for nervousness; and $\mathrm{F}_{1,245}=.693 ; p=.406$ for anger.

As mentioned above, open-ended questions were added to the survey. When analyzing the responses, similarities were found among the Israeli and Russian students. For example, financial and academic study-related responses evidence the following: "due to the current situation, I am worried and anxious about job loss and an inability to get a new job"; "I am scared about not working [since] I still need to pay for my studies"; "it's hard to focus on my studies ... I am nervous about what will happen with tests and it's not easy for me to study online"; "I feel uncertain about my professional future due to the sudden break of routine clinical studies...I fear [conditions] will hold me back and I won't be able to advance professionally...".

COVID-19 mental health-related statements from students of both countries show "I constantly feel depressed and tired during the day... practically doing nothing..."; "I'm stressed primarily about my family and people at risk..."; "my heart races in the evening, and sometimes I feel shortness of breath and pain in my chest..."; and, "I dream about coronavirus and sometimes it's difficult to fall asleep due to stressful thoughts...".

Students were asked if they used tobacco, alcohol, and cannabis to reduce COVID-19 stress or anxiety. Responses show students increased their substance use during the COVID-19 pandemic: "I drink wine more often than usual due to being at home more than the usual..."; "I began to drink often on weekends to forget ..."; "I smoke cigarettes because I'm at home more, feel the need for a release and to compensate for other hardships that I'm dealing

Table 3 Psycho-emotional conditions and COVID-19 fear levels among Israeli and Russian social work students

\begin{tabular}{|c|c|c|c|c|c|c|}
\hline & \multicolumn{3}{|l|}{ Israeli } & \multicolumn{3}{|l|}{ Russian } \\
\hline & \multicolumn{6}{|c|}{ Level of COVID-19 fear } \\
\hline & $\begin{array}{l}\text { Low } \\
(N=48)\end{array}$ & $\begin{array}{l}\text { Medium } \\
(N=56)\end{array}$ & $\begin{array}{l}\text { High } \\
(N=53)\end{array}$ & $\begin{array}{l}\text { Low } \\
(N=39)\end{array}$ & $\begin{array}{l}\text { Medium } \\
(N=41)\end{array}$ & $\begin{array}{l}\text { High } \\
(N=36)\end{array}$ \\
\hline $\begin{array}{c}\text { Depressed, } \\
\%(N)\end{array}$ & $21.3(10)^{* * *}$ & $47.1(24)^{* * * *}$ & $65.4(34)^{* * *}$ & $28.9(11)^{* *}$ & $44.7(17)^{* *}$ & $71.9(23)^{* *}$ \\
\hline $\begin{array}{c}\text { Exhausted, } \\
\%(N)\end{array}$ & $44.7(21)^{* *}$ & $64.7(23)^{* *}$ & $78.4(40)^{* *}$ & $14.3(5)^{* * *}$ & $38.9(14)^{* * *}$ & $58.2(18)^{* * *}$ \\
\hline Lonely, \% $(N)$ & $46.8(22)^{* * *}$ & $58.8(30)^{* * * *}$ & $90.4(47)^{* * * *}$ & $36.1(13)^{*}$ & $47.2(17)^{*}$ & $66.7(20)^{*}$ \\
\hline Nervous, $\%(N)$ & $14.9(7)^{* * *}$ & $47.1(24)^{* * * *}$ & $75.0(39)^{* * *}$ & $31.6(12)^{* * *}$ & $50.0(19)^{* * *}$ & $76.5(28)^{* * *}$ \\
\hline Angry, \% $(N)$ & $19.1(9)^{* * *}$ & $47.1(24) * * *$ & $58.8(30)^{* * *}$ & $25.0(9)^{* *}$ & $56.4(22)^{* *}$ & $56.0(14)^{* * *}$ \\
\hline
\end{tabular}

$* p<.05 ; * * p<.01 ; * * *<.001\left(\chi^{2}\right.$ test $)$ 
Table 4 COVID-19-related fear and emotional conditions

\begin{tabular}{|c|c|c|c|c|}
\hline & $\begin{array}{l}\text { COVID-19 fear } \\
\text { value, mean (SD) }\end{array}$ & df & $t$ & $p$ value \\
\hline \multicolumn{5}{|l|}{ Depressed } \\
\hline Yes $(N=120)$ & $24.5(6.2)$ & 256 & 6.934 & $<.001$ \\
\hline No $(N=142)$ & $19.5(5.3)$ & & & \\
\hline \multicolumn{5}{|l|}{ Exhausted } \\
\hline Yes $(N=132)$ & $24.0(6.2)$ & 249 & 6.076 & $<.001$ \\
\hline No $(N=123)$ & $19.5(5.4)$ & & & \\
\hline \multicolumn{5}{|l|}{ Lonely } \\
\hline Yes $(N=150)$ & $23.7(6.4)$ & 250 & 6.095 & $<.001$ \\
\hline No $(N=105)$ & $19.1(5.1)$ & & & \\
\hline \multicolumn{5}{|l|}{ Nervous } \\
\hline Yes $(N=128)$ & $25.0(6.0)$ & 258 & 8.615 & $<.001$ \\
\hline No $(N=136)$ & $19.0(5.1)$ & & & \\
\hline \multicolumn{5}{|l|}{ Angry } \\
\hline Yes $(N=109)$ & $23.8(5.7)$ & 247 & 5.478 & $<.001$ \\
\hline No $(N=144)$ & $19.8(5.7)$ & & & \\
\hline
\end{tabular}

with..."; "I smoke cannabis every night in order to reduce stress and negative feelings ...in the past I used cannabis only for social events once a month, now I use it daily in the evenings... I have no doubt that my intake is directly related to my need to reduce anxiety and stress...".

\section{Discussion}

The COVID-19 epidemic is a public health emergency of international concern and poses a challenge to psychological resilience worldwide (Wang et al. 2020). During the outbreak, people encountered an invisible enemy with fear, anxiety, and understanding that there is no known cure (Mazza et al. 2020). To a major extent, as hypothesized, findings evidence a considerable amount of response congruence related to fear, mental health, and substance use among the Israeli and Russian students surveyed.

Israeli and Russian social work personnel and students often live in the same community as their clients, and they experience similar traumatic events. However, in emergency situations, they have responsibilities as frontline responders to address the mental health needs of others (Azaiza et al. 2015; Dulmus and Sowers 2012). In this current public health emergency, numerous stories are emerging how social work personnel are responding to the needs of people in ways similar to those from other helping professions like medicine and nursing (O'Leary and Tsui 2020). However, it is also important to recognize they are not immune from mental health-related conditions and substance misuse that may necessitate support to maintain their resilience and well-being.

\section{Limitations and Future Directions}

This study has several limitations. First, an online survey of random respondents weakens generalizability of the study findings. Another limitation is that self-reported psychological and emotional levels of fear, depression, and other conditions may not always be aligned with an 
assessment by mental health professionals. Similarly, respondents might have provided socially desirable responses about their emotional and psychological condition to the situation.

Study findings show student mental health and substance use are affected by a public health emergency. In response, university and college personnel responsible for counseling services should be responsive to addressing student needs, especially those with "front line" responsibilities actively addressing disaster-related health and mental health conditions.

Finally, at the time of preparing this article, COVID-19 fear and related conditions evidence transition, an easing of closure and quarantine in many locations as well as evidence of a second wave of infection. Therefore, follow-up studies are needed to address what some experts are referring to as "the mental health tsunami," a storm surge of consequences, often addressed through the social work profession, that will come as a result of job loss, underemployment, salary loss and debt, illness, death, and a heavy reliance on tobacco, alcohol, opioids, and other substances to cope (Carson et al. 2020).

Acknowledgments The authors of "The Fear of COVID-19 Scale: Development and Initial Validation" published in the International Journal of Mental Health and Addiction are acknowledged. Roi Erel, Michaela Schwartz, Ofri Karni, and Ethan Florentine are thanked for their cooperation with Israeli student data collection. And, special gratitude is expressed to Drs. Toby and Mort Mower for their support of the Ben Gurion University of the Negev - Regional Alcohol and Drug Abuse Research (RADAR) Center.

\section{Compliance with Ethical Standards}

Conflict of Interest The authors declare that they have no conflict of interest.

Ethical Approval The Israeli and Russian investigators received approval from the ethics committees of the two universities involved. These ethics approval processes are equivalent to established regulations to help protect the rights and welfare of human research subjects.

\section{References}

Ahorsu, D. K., Lin, C. Y., Imani, V., Saffari, M., Griffiths, M. D., \& Pakpour, A. H. (2020). The fear of COVID19 scale: development and initial validation. International Journal of Mental Health and Addiction. Retrieved from. https://doi.org/10.1007/s11469-020-00270-8.

Alyami, M., Henning, M., Krägeloh, C. U., \& Alyami, H. (2020). Psychometric evaluation of the Arabic version of the fear of COVID-19 scale. International Journal of Mental Health and Addiction, 1. https://doi. org/10.1007/s11469-020-00316-x.

Azaiza, F., Soffer, M., \& Taubman, D. (2015). Social work education in Israel. The Indian Journal of Social Work, 76(761), 75-94.

Baillie, A. J., Stapinski, L., Crome, E., Morley, K., Sannibale, C., Haber, P., \& Teesson, M. (2010). Some new directions for research on psychological interventions for comorbid anxiety and substance use disorders. Drug and Alcohol Review, 29(5), 518-524.

Bao, Y., Sun, Y., Meng, S., Shi, J., \& Lu, L. (2020). 2019-nCoV epidemic: address mental health care to empower society. The Lancet, 395(10224), e37-e38.

Breault, J. (2006). Protecting Human Research Subjects: The Past Defines the Future. Ochsner Journal 6(1):15-20.

Burdorf, A., Porru, F., \& Rugulies, R. (2020). The COVID-19 (coronavirus) pandemic: consequences for occupational health. Scandinavian Journal of Work, Environment \& Health, 46(3), 229-230. https://doi. org/10.5271/sjweh.3893.

Carson, J., Eyre, H., \& Lavretsky, H. (2020). Dear mental health innovators: the COVID-19 honeymoon is almost over. Psychiatric time. Retrieved from https:/www.psychiatrictimes.com/article/dear-mental-healthinnovators-covid-19-honeymoon-almost-over. 
Chen, W., Wang, Q., Li, Y., Yu, H., Xia, L., \& Zhang, M. (2020). Overview of early containment strategies for new coronavirus pneumonia in China. Chinese Journal of Preventive Medicine, 54. https://doi.org/10.3760 /cma.j.issn.0253-9624.2020.03.003.

Cronbach, L. J., \& Shavelson, R. J. (2004). My current thoughts on coefficient alpha and successor procedures. Educational and Psychological Measurement, 64(3), 391-418.

Dulmus, C. N., \& Sowers, K. M. (2012). The profession of social work: guided by history, led by evidence. Hoboken: John Wiley \& Sons.

Dunn, T. J., Baguley, T., \& Brunsden, V. (2014). From alpha to omega: a practical solution to the pervasive problem of internal consistency estimation. British Journal of Psychology, 105(3), 399-412.

Grubic, N., Badovinac, S., \& Johri, A. M. (2020). Student mental health in the midst of the COVID-19 pandemic: a call for further research and immediate solutions. International Journal of Social Psychiatry, 0020764020925108 .

Harper, C. A., Satchell, L. P., Fido, D., \& Latzman, R. D. (2020). Functional fear predicts public health compliance in the COVID-19 pandemic. International Journal of Mental Health and Addiction. https://doi.org/10.1007/s11469-020-00281-5.

JASP (2020). A fresh way to do statistics. Retrieved from https://jasp-stats.org/.

Johns Hopkins University of Medicine (JHUM) (2020), World Map-Global Deaths. Retrieved from https://coronavirus.jhu.edu/map.html.

Kang, L., Li, Y., Hu, S., Chen, M., Yang, C., \& Yang, B. (2020). The mental health of medical workers in Wuhan, China dealing with the 2019 novel coronavirus. The Lancet Psychiatry, 7(3), e14.

Lin, C. Y. (2020). Social reaction toward the 2019 novel coronavirus (COVID-19). Social Health and Behavior, $3(1), 1$.

Mazza, M., Marano, G., Lai, C., Janiri, L., \& Sani, G. (2020). Danger in danger: Interpersonal violence during COVID-19 quarantine. Psychiatry Research, 113046. https://doi.org/10.1016/j.psychres.2020.113046.

McDonald, R. P. (1999). Test theory: a unified treatment. Mahwah: Lawrence Erlbaum.

Nanshan, C., Min, Z., Xuan, D., Jieming, Q., Fengyun, G., et al. (2020). Epidemiological and clinical characteristics of 99 cases of 2019 novel coronavirus pneumonia in Wuhan, China: a descriptive study. The Lancet, 395(10223), 507-513.

O'Leary, P., \& Tsui, M. S. (2020). Ten gentle reminders to social workers in the pandemic. International Social Work, 63(3), 273-274.

Pakpour, A. H., \& Griffiths, M. D. (2020). The fear of COVID-19 and its role in preventive behaviors. Journal of Concurrent Disorders http://irep.ntu.ac.uk/id/eprint/39561.

Reznik, A., Gritsenko, V., Konstantinov, V., Khamenka, N., \& Isralowitz, R. (2020). COVID-19 fear in Eastern Europe: validation of the fear of COVID-19 scale. International Journal of Mental Health and Addiction. https://doi.org/10.1007/s11469-020-00283-3.

Satici, B., Gocet-Tekin, E., Deniz, M. E., \& Satici, S. A. (2020). Adaptation of the fear of COVID-19 scale: its association with psychological distress and life satisfaction in Turkey. International Journal of Mental Health and Addiction, 10. https://doi.org/10.1007/s11469-020-00294-0.

Torales, J., O’Higgins, M., Castaldelli-Maia, J. M., \& Ventriglio, A. (2020). The outbreak of COVID-19 coronavirus and its impact on global mental health. International Journal of Social Psychiatry, 0020764020915212 . Retrieved from. https://doi.org/10.1177/0020764020915212.

Wang, C., Pan, R., Wan, X., Tan, Y., Xu, L., Ho, C. S., \& Ho, R. C. (2020). Immediate psychological responses and associated factors during the initial stage of the 2019 coronavirus disease (COVID-19) epidemic among the general population in China. International Journal of Environmental Research and Public Health, 17(5), 1729. https://doi.org/10.3390/ijerph17051729.

World Health Organization (WHO) (2020). Process of translation and adaptation of instruments. Retrieved from https://www.who.int/substance_abuse/research_tools/translation/en/.

Publisher's Note Springer Nature remains neutral with regard to jurisdictional claims in published maps and institutional affiliations. 